\title{
Perbedaan Pencapaian Kompetensi Mahasiswa Ners (Komunikasi, Keterampilan dan Perilaku Profesional) Antara Stase Keperawatan Anak Dengan Keperawatan Maternitas Sesudah Intervensi Metode Bimbingan One Minute Preceptor (OMP) pada Preceptor di Kota Bengkulu
}

\author{
Emi Pebriani ${ }^{1 *}$, Yulastri Arif ${ }^{2}$, Mira Susanti ${ }^{3}$ \\ ${ }^{1}$ Program Studi Magister Keperawatan Kekhususan Manajemen Keperawatan Universitas Andalas \\ ${ }^{2,3}$ Program Studi Magister Ilmu Keperawatan Universitas Andalas \\ *Correspondence email: emipebriani@yahoo.com
}

\begin{abstract}
Abstrak. Kompetensi perawat professional diukur melalui uji kompetensi yang diselenggarakan oleh Kementrian riset, teknologi dan pendidikan tinggi (Kemenristek Dikti, 2015). Hasil evaluasi yang didapatkan menunjukkan bahwa dari tahun ke tahun mengalami tingkat kelulusan yang fluktuatif. Pada Tahun 2016 angka kelulusan 53,46\%, Tahun 2017 angka kelulusan 50,58\%, Tahun 2018 angka kelulusan 50,38\% dan pada Tahun 2019 angka kelulusan ukom 64,6\% (Kemenristek Dikti, 2019). Data di atas menunjukkan tingkat kelulusan nasional uji kompetensi perawat masih perlu ditingkatkan. Penelitian bertujuan untuk membandingkan efektifitas metode bimbingan One Minute Preceptor (OMP) terhadap kompetensi stase Keperawatan Anak dan Keperawatan Maternitas pada Mahasiswa Profesi Ners Universitas Dehasen Kota Bengkulu. Jenis penelitian adalah Jenis penelitian ini adalah kuantitatif dengan desain quasi experimen post test only design. Sampel dalam penelitian ini berjumlah 30 responden. Pengambilan sampel dengan total sampling. Rerata nilai post test pengetahuan, sikap, keterampilan dan kumulatif preceptor lebih tinggi dibandingkan dengan nilai pre test. Rerata pencapain nilai komunikasi, keterampilan dan perilaku profesional mahasiswa stase keperawatan maternitas lebih tinggi daripada mahasiswa stase keperawatan anak. Ada perbedaan pencapaian kompetensi mahasiswa ners (komunikasi, keterampilan dan perilaku profesional) antara stase keperawatan anak dengan keperawatan maternitas sesudah intervensi metode bimbingan One Minute Preceptor (OMP) pada preceptor. Diharapkan preceptor dapat menerapkan metode metode bimbingan One Minute Preceptor (OMP) pada setiap mahasiswa yang sedang malaksanakan praktek.
\end{abstract}

Kata kunci: Metode Bimbingan One Minute Preceptor; Mahasiswa Ners Stase Keperawatan Anak; Maternitas

Abstract. Professional nurse competence is measured through a competency test conducted by the Ministry of Research, Technology and Higher Education (Kemenristek Dikti, 2015). The evaluation results obtained show that from year to year the graduation rate fluctuates. In 2016 the graduation rate was 53.46\%, in 2017 the graduation rate was 50.58\%, in 2018 the graduation rate was 50.38\% and in 2019 the graduation rate for ukom was 64.6\% (Kemenristek Dikti, 2019). The data above shows that the national pass rate for the nurse competency test still needs to be improved. This study aims to compare the effectiveness of the One Minute Preceptor (OMP) guidance method on the competency of the stage of Child Nursing and Maternity Nursing in Nursing Profession Students at Dehasen University, Bengkulu City. This type of research is the type of this research is quantitative with a quasi experimental design post test only design. The sample in this research was 30 students. Sampling with total sampling. The mean post-test scores for knowledge, attitudes, skills and cumulative preceptors were higher than the pre-test scores. The average achievement of the communication scores, skills and professional behavior of the students in the maternity nursing stage was higher than that of the children in the nursing stage. There are differences in the achievement of student competencies (communication, skills and professional behavior) between the stage of child nursing and maternity nursing after the intervention of the One Minute Preceptor (OMP) guidance method on the preceptor. It is expected that the preceptor can apply the One Minute Preceptor (OMP) guidance method to every student who is carrying out his practice.

Keywords: Managerial Functions of Unit Leaders; Patient Safety Culture and Professional Care Givers

\section{PENDAHULUAN}

Perawat merupakan tenaga professional pemberi asuhan di bidang kesehatan (Rohmah \& Walid, 2019). Menurut Undang - Undang No 38 Tahun 2014 perawat adalah seseorang yang telah lulus pendidikan tinggi, baik di dalam maupun luar negeri, diakui oleh pemerintah sesuai dengan ketentuannya (Adiwidya, 2015). Jadi, perawat adalah tenaga kesehatan yang telah lulus dari perguruan tinggi keperawatan dengan kompotensi sesuai dengan kerangka kualifikasi pendidikan Indonesia. Namun, faktanya di lapangan masih sangat banyak ditemukan permasalahan terkait dengan kompetensi perawat.

Kompetensi adalah suatu gambaran tentang hal harus dilakukan seseorang agar dapat melaksanakan pekerjaannya dengan sebaik mungkin. Kompetensi adalah kemampuan mencakup pengetahuan, keterampilan dan sikap dalam menyelesaikan sesuatu pekerjaan dengan standar kinerja yang telah ditetapkan (PPNI, 2012). Menurut Kemenkes RI (2020), kompetensi perawat mencakup pengetahuan, sikap dan keterampilan (soft dan hard skill). Kompetensi perawat 
Emi Pebriani, Yulastri Arif dan Mira Susanti, Perbedaan Pencapaian Kompetensi Mahasiswa Ners (Komunikasi, Keterampilan dan Perilaku Profesional) Antara Stase Keperawatan Anak Dengan Keperawatan Maternitas Sesudah Intervensi Metode Bimbingan One Minute Preceptor (OMP) pada Preceptor di Kota Bengkulu

dalam berkomunikasi, keterampilan dan perilaku profesional dapat dinilai dengan observasi. Sehingga, kompetensi perawat dapat diartikan suatu kemampuan yang dimiliki perawat dalam melaksanakan asuhan keperawatan di bidangnya.

Kompetensi perawat professional diukur melalui uji kompetensi yang diselenggarakan oleh Kementrian riset, teknologi dan pendidikan tinggi (Kemenristek Dikti, 2015). Perawat yang telah lulus uji kompetensi akan mendapatkan sertifikat lulus uji kompetensi dan dapat memiliki surat tanda registrasi (Permendikbud No.2 tahun 2020). Namun hingga saat ini, masih banyak permasalahan yang ditemui pada SDM perawat dalam mencapai kelululusan uji kompetensi dengan baik.

Hasil evaluasi yang didapatkan menunjukkan bahwa dari tahun ke tahun mengalami tingkat kelulusan yang fluktuatif. Pada Tahun 2016 angka kelulusan 53,46\%, Tahun 2017 angka kelulusan 50,58\%, Tahun 2018 angka kelulusan 50,38\% dan pada Tahun 2019 angka kelulusan ukom 64,6\% (Kemenristek Dikti, 2019). Data di atas menunjukkan tingkat kelulusan nasional uji kompetensi perawat masih perlu ditingkatkan.

Kelulusan uji kompetensi perawat dapat dipengaruhi dari berbagai faktor. Faktor yang memiliki pengaruh signifikan terhadap kemampuan peserta untuk dapat lulus uji kompetensi ialah faktor kognitif, akademik dan individu (Sears, 2015). Menurut Kholifah \& Kusumawati (2016) faktor yang mempengaruhi yaitu persiapan yang matang dengan memperkenalkan kisikisi uji kompetensi dan memberikan kesempatan untuk menjelaskan pemaparan terhadap praktik klinik. Ahmar (2020) menyatakan faktor yang dapat menunjang dalam capaian kompetensi ialah lingkungan belajar dan metode bimbingan. Jadi, faktor yang mempengaruhi kompetensi perawat adalah persiapan yang matang, kesempatan untuk menjelaskan pemaparan terhadap praktik klinik, lingkungan belajar dan metode yang digunakan dalam pembelajaran klinik.

Pembelajaran klinik sangat menentukan kualitas capaian pembelajaran mahasiswa keperawatan (Abreu \& Interpeler, 2015). Pembentukan pembelajaran yang baik antara teori dan praktik saling melengkapi dan harus didukung oleh pembimbing klinik (preceptor) (Teferra $\&$ Mengistu, 2019). Dengan demikian, preceptor dapat dikatakan sebagai perwujudan pelaksanaan kurikulum pendidikan keperawatan yang diberikan pembimbing klinik dan dapat menjadi bekal peserta didik agar mengaplikasikan ilmu berdasarkan kompetensi yang dimiliki.

Keunggulan belajar klinik didapatkan dari preceptor, karena dengan adanya preceptor, pembelajaran akan lebih berfokus pada masalah nyata sehingga memotivasi mahasiswa untuk berpartispasi aktif dalam pencapaian kompetensi (Sulung, 2016). Berfikir kritis dan mendorong tindakan serta sikap profesional (Li-Ling, 2014). Jadi, agar mahasiswa dapat mencapai kompetensinya preceptor sebagai mentor hendaknya memiliki keterampilan, pengetahuan dan tanggung jawab yang tinggi.

Tanggung jawab seorang preceptor adalah untuk mengelola, mendidik dan mendukung mahasiswa selama praktik klinik (Abreu \& Interpeler, 2015). Menurut Ismail (2016) hal yang penting dari preceptor adalah memfasilitasi pembelajaran, sehingga diperlukan perilaku dan keterampilan yang baik. Seorang preceptor harus memiliki knowladge, clinical competency, skill in clinical teaching dan interpersonal relationship with student. Seorang preceptor juga harus memiliki pengetahuan dan cara untuk berinteraksi kepada peserta didik agar peserta didik dapat mencontoh dalam melakukan keahlian klinis (Gardner \& Suplee, 2017). Namun, pada kenyataannya pembelajaran klinik selama ini masih menemui berbagai hambatan dan kendala.

Beberapa kendala yang dialami yaitu preseptor belum memahami tujuan dari bimbingan sehingga mereka kesulitan untuk melaksanakan perannya, masih kurangnya pelatihan tentang preceptorship (Ward \& McComb, 2017). Sedangkan menurut McSharry \& Lathlean, (2017) ketersediaan waktu yang baik dalam bimbingan kepada mahasiswa merupakan dasar pembelajaran yang efektif. Kurangnya waktu interaksi antara pembimbing dan mahasiswa membuat pembimbing kurang merasakan manfaat dari bimbingan untuk meningkatkan kompetensi mahasiswa (Wulandari, 2013).

Kurangnya waktu interaksi antara preceptor dengan mahasiswa dapat disebabkan oleh karena beban kerja yang dimiliki oleh preceptor. Mahanani (2014) menyatakan bahwa seorang preceptor akan siap untuk bekerja dengan lebih baik apabila beban kerja yang dimiliki sesuai dengan kemampuannya. Beban kerja perawat preceptor lebih tinggi dikarenakan selain dituntut untuk memberikan bimbingan klinik pada mahasiswa, preceptor juga harus menjalankan tugasnya dalam memberikan asuhan keperawatan pada pasien. Sampai saat ini juga manajemen rumah sakit merasa kesulitan untuk penataan tenaga seorang perawat preceptor untuk tidak difungsikan sebagai perawat pelaksana karena jumlah SDM yang belum memenuhi, sehingga preceptor diharuskan dapat melaksanakan dengan seimbang kedua tugas yakni sebagai pelaksana dan pembimbing klinik (preceptor).

Melihat keterbatasan dan tugas preceptor, maka doperlukan metode bimbingan klinik yang dapat mengatasi permasalahan tersebut. Metode bimbingan klinik merupakan cara mengorganisir dan menyajikan petunjuk dalam mengarahkan individu untuk mencapai tujuan menjadi tenaga profesional yang mandiri. Beberapa metode pembelajaran klinik antara lain yaitu metode pengalaman, penyelesaian masalah, konferensi, observasi, menggunakan media, self directed, sistem 
Emi Pebriani, Yulastri Arif dan Mira Susanti, Perbedaan Pencapaian Kompetensi Mahasiswa Ners (Komunikasi, Keterampilan dan Perilaku Profesional) Antara Stase Keperawatan Anak Dengan Keperawatan Maternitas Sesudah Intervensi Metode Bimbingan One Minute Preceptor (OMP) pada Preceptor di Kota Bengkulu

yang difokuskan pada praktek, dan preseptorship (Yusuf, 2015). Sedangkan menurut Suhoyo (2016) beberapa metode bimbingan yang efektif dan efisien adalah Bedside Teaching, SNAPP model, One Minute Preceptor, Feedback dan Reflection.

Bedside Teaching merupakan pembelajaran yang dilakukan peserta didik berhadapan langsung dengan pasien memiliki spesifik tujuan dan keterampilan (Cholifah, Rusnoto, \& Hartinah, 2015). Kelebihan dari metode ini mampu meningkatkan pencapaian kompetensi klinik, kepercayaan diri dan kesadaran peserta didik (Peters \& Cate, 2014). Namun, metode ini memiliki kelemahan yaitu dosen/pembimbing klinik yang kurang memiliki waktu dan tidak adanya ruang buat diskusi.

Metode bimbingan SNAPPS terbukti efektif dalam meningkatkan kemampuan mahasiswa untuk memecahkan masalah serta mengintegrasikan teori dan praktek (Tuasikal \& Mukaromah, 2019). Metode ini memiliki kelebihan dapat dimodifikasi untuk situasi belajar yang lain, dapat mendorong inisiatif pelajar dan dapat digunakan pada pembelajaran berbasis pengalaman (Nursalam, 2008). Namun, metode ini pun memiliki kekurangan yaitu adanya perbedaan tingkat penalaran dan keterampilan mahasiswa.

Metode bimbingan Feedback dan Reflection adalah suatu proses metakognitif yang berlangsung sebelum, selama dan sesudah situasi tertentu (Pamungkasari, 2017). Metode ini bertujuan untuk mengembangkan pemahaman yang lebih baik mengenai situasi yang dihadapi sehingga dapat dijadikan pelajaran di masa yang akan datang (Dwita, 2015). Adapun kelemahan dari metode ini adalah keikutsertaan yang rendah, adanya rasa tidak nyaman apabila kekurangannya dapat diketahui oleh orang lain dan kurangnya waktu dalam melakukan refleksi.

Metode bimbingan One Minute Preceptor (OMP) merupakan suatu metode bimbingan efektif yang dapat digunakan dalam waktu yang terbatas (Fagundes et al., 2020) Metode bimbingan klinik ini merupakan metode yang tidak terlalu rumit dan dinilai tepat sasaran untuk mengatasi permasalahan keterbatasan waktu yang dimiliki preceptor (Seki et al., 2016). Sehingga perlu dilakukannya penataan sistem pembelajaran yang lebih baik.

Penataan sistem pembelajaran dilakukan melalui pengembangan dan penerapan model pembelajaran/bimbingan klinis yang efektif. Menurut Tuasikal (2020) metode OMP adalah salah satu metode bimbingan yang efektif meningkatkan kepuasan pendidik dalam pengajaran dan meningkatkan kompetensi. Model OMP mempromosikan metode bimbingan, instruksi dan umpan balik kepada mahasiswa dengan cara yang efisien dan dalam konteks klinis yang lebih besar (Swartz, 2016). Sedangkan menurut Triwijayanti (2016) mengatakan bahwa OMP dapat meningkatkan kemampuan dalam belajar mengajar, lebih efektif, adanya umpan balik positif, berfikir kritis dan mengembangkan keterampilan dan sikap profesional. Pendekatan metode ini memungkinkan pembimbing memiliki keuntungan dalam memanfaatkan waktu yang tersedia.

Disebut OMP karena waktu singkat yang tersedia untuk mengajar di lingkungan klinis dan kerangka yang sederhana untuk mengajar setiap hari selama merawat pasien. mengingat waktu yang dimiliki pembimbing klinik umumnya singkat karena banyaknya tugas yang harus diemban (Lockspeiser \& Kaul, 2015). Berdasarkan hasil penelitian yang dilakukan Syarli dkk (2020), yaitu Penerapan model pembelajaran klinik OMP pada mata kuliah manajemen keperawatan memberikan pengaruh yang positif terhadap meningkatnya pencapaian kompetensi mahasiswa.

Keuntungan khusus dari model OMP menurut penelitian Swartz (2016) adalah dapat memberikan kerangka kerja yang berharga dan andal untuk membangun diskusi antara mahasiswa dan pembimbing klinik dengan waktu yang terbatas. Menurut kajian sistematik Gatewood \& Gagne (2019) menyimpulkan model OMP sebagai model pembelajaran yang telah terbukti dapat meningkatkan teknik pengajaran termasuk umpan balik dan penilaian penalaran klinis mahasiswa. Sedangkan menurut penelitian Arya (2018) menyimpulkan bahwa OMP dapat menjadi metode yang efektif dalam presentasi kasus serta dapat meningkatkan keterampilan dan pengalaman belajar bagi mahasiswa residensi pascasarjana peminatan keperawatan. Jadi metode OMP merupakan salah satu metode yang dapat digunakan untuk meningkatkan kompetensi mahasiswa dalam menjalankan stase keperawatan dengan waktu yang singkat dan efektif dilakukan pada masa pandemi ini.

Stase keperawatan keperawatan yang dijalankan mahasiswa di klinik mempengaruhi hasil pencapaian evaluasi kompetensinya. Jumlah soal yang diujikan dalam uji kompetensi yaitu 180 soal yang berbeda-beda. Persentase dan asumsi soal untuk masing-masing bidang berdasarkan blue print uji kompetensi yaitu materi Keperawatan Medikal Bedah 25-37\% (56 soal), Keperawatan Maternitas 8-14\% (19 soal), Keperawatan Anak 8-14\% (19 soal), Keperwatan Jiwa 8-14\% (19 soal), Keperawatan Gerontik 3-9\% (12 soal), Keperawatan Keluarga 8-14\% (19 soal), Manajemen Keperawatan 3-9\% (12 soal), Keperawatan Gawat Darurat 3-9\% (12 soal) dan Keperawatan Komunitas 39\% (12 soal) (Tim Visi Adiwidya, 2015).

Provinsi Bengkulu terletak di sebelah barat pegunungan Bukit Barisan, memanjang dari perbatasan Provinsi Sumatera Barat sampai ke perbatasan Provinsi Lampung. Di Provinsi Bengkulu terdapat 4 perguruan tinggi kesehatan yang memiliki program studi program profesi ners yaitu Universitas Muhamadiyah Bengkulu 
Emi Pebriani, Yulastri Arif dan Mira Susanti, Perbedaan Pencapaian Kompetensi Mahasiswa Ners (Komunikasi, Keterampilan dan Perilaku Profesional) Antara Stase Keperawatan Anak Dengan Keperawatan Maternitas Sesudah Intervensi Metode Bimbingan One Minute Preceptor (OMP) pada Preceptor di Kota Bengkulu

dengan hasil kelulusan uji kompetensi periode November 2019 31,25\%, STIKes Tri Mandiri Sakti $55,55 \%$, STIKes Bakti Husada 55,69\% dan Universitas Dehasen Bengkulu 65,33\%.

Berdasarkan hasil wawancara yang dilakukan pada preceptor dan Kaprodi Profesi Ners Universitas Dehasen Bengkulu, metode pembelajaran klinik yang saat ini digunakan adalah metode preceptorship, seluruh preceptor klinik yang bekerjasama dengan Universitas Dehasen Bengkulu sudah dibekali dengan pelatihan preceptorship. Beberapa preceptor mengatakan metode bimbingan klinik preceptorship sudah didapatkan namun belum dilakukan secara optimal dan masih adanya kendala dalam pelaksanaan, seperti keterbatasan waktu dan tenaga preceptor dalam membimbing, keterbatasan jumlah preceptor dan banyaknya jumlah mahasiswa di setiap stase seperti stase manajemen, stase anak, stase maternitas, stase gadar dan stase keperawatan medikal bedah (KMB).

Berdasarkan studi pendahuluan yang dilakukan oleh peneliti Hari Kamis, 10 September 2020 pada 8 mahasiswa Universitas Dehasen Bengkulu yang tidak lulus uji kompetensi periode Agustus, peneliti mendapatkan data bahwa 7 dari 8 mahasiswa tersebut mengatakaan materi soal yang paling banyak tidak terjawab adalah soal Anak dan Maternitas. Sementara pada stase keperawatan anak dan maternitas memiliki persentase soal $8-14 \%$ dengan asumsi soal 19 soal. Hal ini mengindikasikan bahwa penyebab turunnya persentase kelulusan mahasiswa adalah dari 2 stase materi keperawatan tersebut.

Berdasarkan latar belakang dan fenomena tersebut, maka peneliti tertarik meneliti tentang "Studi perbandingan: pengaruh metode bimbingan One Minute Preceptor (OMP) terhadap kompetensi stase Keperawatan Anak dan Keperawatan Maternitas pada Mahasiswa Profesi Ners Universitas Dehasen Kota Bengkulu".

\section{METODE}

Penelitian ini adalah penelitian kuantitatif dengan desain quasi experimen post test only design. Sampel dalam penelitian ini berjumlah 30 responden. Pengambilan sampel dengan total sampling.

HASIL DAN PEMBAHASAN

Rerata Perbedaan Pencapaian Kompetensi Mahasiswa Ners (Komunikasi, Keterampilan dan Perilaku Profesional) antara Stase Keperawatan Anak dengan Keperawatan Maternitas Sesudah Intervensi Metode Bimbingan One Minute Preceptor (OMP) pada Preceptor
Tabel 1. Perbandingan pencapaian kompetensi mahasiswa ners (komunikasi, keterampilan dan perilaku profesional)

\begin{tabular}{clcccc}
\hline \multirow{2}{*}{ No } & \multirow{2}{*}{ Kompetensi } & \multicolumn{2}{c}{ Stase } & \multirow{2}{*}{ Selisih } & \multirow{2}{*}{ p Value } \\
\cline { 3 - 4 } & & Anak & Maternitas & & \\
\hline 1 & Komunikasi & 14.00 & 17.07 & 3.07 & 0.002 \\
2 & Keterampilan & 36.13 & 41.73 & 5.390 & 0.008 \\
3 & Perilaku Profesional & 17.07 & 24.40 & 10.81 & 0.010 \\
& Kompetensi & 67.20 & 83.20 & 16.00 & 0.014 \\
\hline
\end{tabular}

Tabel di atas menunjukkan tentang perbandingan pencapaian kompetensi mahasiswa ners (komunikasi, keterampilan dan perilaku profesional) antara stase keperawatan anak dengan keperawatan maternitas sesudah intervensi metode bimbingan One Minute Preceptor (OMP) pada preceptor dengan uji statistik tindependen didapati skor rata-rata komunikasi mahasiswa stase keperawatan anak 14,00, mahasiswa stase keperawatan maternitas 17,07 dengan $\mathrm{p}$ value $0,002(\mathrm{p}<0,05)$ dan selisih rerata 3,07 yang artinya ada perbedaan komunikasi mahasiswa stase keperawatan anak dengan mahasiswa stase keperawatan maternitas.

Kemudian skor rata-rata keterampilan mahasiswa stase keperawatan anak 36,13, mahasiswa stase keperawatan maternitas 41,73 dengan $\mathrm{p}$ value $0,008(\mathrm{p}<0,05)$ dan selisih rerata 5,60 yang artinya ada perbedaan keterampilan mahasiswa stase keperawatan anak dengan mahasiswa stase keperawatan maternitas.

Kemudian skor rata-rata perilaku profesional mahasiswa stase keperawatan anak 17,07, mahasiswa stase keperawatan maternitas 24,40 dengan $\mathrm{p}$ value $0,010(\mathrm{p}<0,05)$ dan selisih rerata 7,33 yang artinya ada perbedaan perilaku profesional mahasiswa stase keperawatan anak dengan mahasiswa stase keperawatan maternitas.

Selanjutnya secara kumulatif didapati skor ratarata mahasiswa stase keperawatan anak 67,20, mahasiswa stase keperawatan maternitas 83,20 dengan dengan $\mathrm{p}$ value $0,014(\mathrm{p}<0,05)$ dan selisih rerata 16,00 yang artinya ada perbedaan pencapaian kompetensi mahasiswa ners (komunikasi, keterampilan dan perilaku profesional) antara stase keperawatan anak dengan keperawatan maternitas sesudah intervensi metode bimbingan One Minute Preceptor (OMP) pada preceptor.

\section{Pembahasan}

1. Pencapaian Kompetensi Mahasiswa Ners (Komunikasi, Keterampilan dan Perilaku Profesional) Stase Keperawatan Anak dan Maternitas Sesudah Intervensi Metode Bimbingan One Minute Preceptor (OMP) pada Preceptor

a. Komunikasi

Berdasarkan hasil penelitian yang telah dilakukan tentang komuniksi mahasiswa sesudah intervensi metode bimbingan One Minute 
Preceptor (OMP) pada preceptor, peneliti mendapati hasil bahwa rerata komunikasi mahasiswa stase keperawatan anak adalah 14,00 (skor total 20). Sedangkan rerata komunikasi mahasiswa stase keperawatan maternitas adalah 17,07 (skor total 20).

Item observasi tentang komunikasi mahasiswa, nilai setiap item penilaian komunikasi sudah cukup tinggi, namun dari 3 item penilaian tersebut, nilai terendah adalah kuesioner nomor 3, yaitu tentang dokumentasi secara benar, untuk mahasiswa stase keperawatan anak pencapaiannya hanya $66,7 \%$ dan untuk mahasiswa stase keperawatan maternitas baru mencapai 75,6\%.

Dokumentasi merupakan suatu bentuk komunikasi tertulis yang berisikan tentang data, status dan tindakan yang sudah dilakukan. Dokumentasi keperawatan adalah suatu catatan yang memuat seluruh data yang dibutuhkan untuk menentukan diagnosis keperawatan, perencanaan keperawatan, tindakan keperawatan, dan penilaian keperawatan yang disusun secara sistematis, valid dan dapat dipertanggungjawabkan secara moral dan hukum (Mulyanti, 2017).

Dokumentasi keperawatan adalah suatu bukti pelayanan keperawatan profesional yang mencakup pengkajian, diagnosis keperawatan, perencanaan keperawatan, tindakan dan evaluasi, menggambarkan kondisi kesehatan pasien secara keseluruhan

Pendokumentasian merupakan suatu kegiatan pencatatan, pelaporan atau merekam suatu kejadian serta aktivitas yang dilakukan dalam bentuk pemberian pelayanan yang dianggap penting dan berharga (Prabowo, 2017).

Menurut asumsi peneliti, kegiatan pendokumentasian yang tidak dilakukan dengan lengkap dapat menurunkan mutu pelayanan keperawatan, hal ini dikarenakan perawat akan kesulitan dalam mengidentifikasi sejauh mana tingkat keberhasilan asuhan keperawatan yang telah diberikan (Dalami, 2011). Menurut Prakosa (2016) dalam penelitiannya menyatakan bahwa pendokumentasian yang tidak ditulis dengan lengkap juga memberikan kerugian bagi klien karena informasi tentang kesehatan klien terabaikan. Lestari (2014) dalam penelitiannya menjelaskan bahwa jika dokumentasi tidak dilakukan maka akan berdampak pada tindakan keperawatan yang tidak akurat.

Menurut asumsi peneliti, kualitas asuhan keperawatan dapat tercermin dari dokumentasi proses keperawatan. Dokumentasi dalam keperawatan memiliki peranan penting terhadap segala macam tuntutan masyarakat yang semakin kritis dan mempengaruhi kesadaran masyarakat akan hak-haknya dari suatu unit kesehatan. Oleh sebab itu maka peneliti menyarankan pada preceptor untuk dapat memberikan materi tentang dokumentasi keperawatan pada mahasiswa hingga seluruh mahasiswa memahami seluruh aspek dalam proses keperawatan yang akan didokumentasikan.

b. Keterampilan

Berdasarkan hasil penelitian yang telah dilakukan tentang keterampilan mahasiswa sesudah intervensi metode bimbingan One Minute Preceptor (OMP) pada preceptor, peneliti mendapati hasil bahwa rerata keterampilan mahasiswa stase keperawatan anak adalah 36,13 (skor total 50). Sedangkan rerata keterampilan mahasiswa stase keperawatan maternitas adalah 17,07 (skor total 41,73).

Menurut Tuasikal (2020) metode OMP adalah salah satu metode bimbingan yang efektif meningkatkan kepuasan pendidik dalam pengajaran dan meningkatkan kompetensi. Model OMP mempromosikan metode bimbingan, instruksi dan umpan balik kepada mahasiswa dengan cara yang efisien dan dalam konteks klinis yang lebih besar (Swartz, 2016).

Berdasarkan 5 item observasi tentang keterampilan mahasiswa, nilai setiap item penilaian keterampilan sudah cukup tinggi, namun dari 5 item penilaian tersebut, nilai terendah adalah kuesioner nomor 4, yaitu tentang menciptakan keamanan dan kenyamanan, untuk mahasiswa stase keperawatan anak pencapaiannya hanya $65,3 \%$ dan untuk mahasiswa stase keperawatan maternitas baru mencapai 78,7\%.

Keamanan dan kenyamanan adalah dua hal yang saling berkaitan. Jika seseorang sudah merasa aman, maka akan menimbulkan rasa nyaman. Kenyamanan pasien di rumah sakit selama menjalani proses pengobatan akan didapatkan jika rasa aman sudah terpenuhi. Tujuan dari aman dan nyaman ini hanya demi sebuah kelancaran dalam mendapatkan asuhan keperawatan.

Menurut asumsi peneliti, setiap elemen yang berperan dalam proses pemberian pengobatan terhadap pasien sebaiknya selalu memperhatikan prinsip keamanan dan kenyamanan pasien. Oleh sebab itu maka untuk menciptakan keamanan dan kenyamanan pada pasien, tidak hanya bertumpu pada perawat, namun semua sumber daya manusia yang berinteraksi dengan pasien turut berperan dan 
Emi Pebriani, Yulastri Arif dan Mira Susanti, Perbedaan Pencapaian Kompetensi Mahasiswa Ners (Komunikasi, Keterampilan dan Perilaku Profesional) Antara Stase Keperawatan Anak Dengan Keperawatan Maternitas Sesudah Intervensi Metode Bimbingan One Minute Preceptor (OMP) pada Preceptor di Kota Bengkulu

harus memahami prinsip yang keamanan dan kenyamanan.

c. Perilaku Profesional

Berdasarkan hasil penelitian yang telah dilakukan tentang perilaku profesional mahasiswa sesudah intervensi metode bimbingan One Minute Preceptor (OMP) pada preceptor, peneliti mendapati hasil bahwa rerata perilaku profesional mahasiswa stase keperawatan anak adalah 17,07 (skor total 30). Sedangkan rerata keterampilan mahasiswa stase keperawatan maternitas adalah 24,00 (skor total 30).

Berdasarkan 5 item observasi tentang perilaku profesional mahasiswa, nilai setiap item penilaian perilaku profesional sudah cukup tinggi, namun dari 5 item penilaian tersebut, nilai terendah adalah kuesioner nomor 3, yaitu tentang mengambil inisiatif dalam situasi belajar, untuk mahasiswa stase keperawatan anak pencapaiannya hanya $44,4 \%$ dan untuk mahasiswa stase keperawatan maternitas baru mencapai $76,0 \%$.

Inisiatif dalam situasi belajar merupakan bentuk kemandirian belajar dengan adanya dorongan diri sendiri, kesadaran diri, untuk mencapai tujuan belajar, mahasiswa berusaha untuk meningkatkan tanggung jawab dalam mengambil berbagai keputusan, melibatkan berbagai sumber daya dan aktivitas seperti membaca sendiri, belajar kelompok, latihan dan kegiatan korespondensi.

Menurut Lipton \& Huble (2015) seseorang yang mempunyai kemandirian belajar dapat dilihat dari kegiatan belajarnya, seperti tidak perlu diingatkan untuk belajar dan kegiatan belajar dilaksanakan atas inisiatif dirinya sendiri, merencanakan dan memilih kegiatan belajar sendiri, belajar secara kritis, logis dan penuh keterbukaan dan penuh percaya diri.

Menurut asumsi peneliti untuk menciptakan inisiatif dalam situasi belajar pada mahasiswa yang sedang melaksanakan praktek klinik, diperlukan peran serta preceptor berupa penjelasan mengenai pentingnya kegiatan pembelajaran dilaksanakan, manfaat belajar dari inisiatif sendiri serta dampak negatif jika mahasiswa tidak memiliki inisiatif untuk belajar. Oleh karena itu maka diharapkan preceptor dapat menghadirkan kesadaran dari diri mahasiswa sehingga mahasiswa tergerak dan berusaha untuk melaksanakan pembelajaran berdasarkan keinginan sendiri.

Selanjutnya berdasarkan analisis kuesioner, peneliti juga mendapatkan hasil pencapaian kompetensi mahasiswa ners (komunikasi, keterampilan dan perilaku profesional) stase keperawatan anak dan maternitas sesudah intervensi metode bimbingan One Minute Preceptor (OMP) pada Preceptor dari 67,20 hingga 83,20. Oleh sebab itu maka peneliti berharap kegiatan metode bimbingan One Minute Preceptor (OMP) terus berjalan sehingga komunikasi, keterampilan dan perilaku profesional mahasiswa semakin meningkat.

2. Perbandingan Pencapaian Kompetensi Mahasiswa Ners (Komunikasi, Keterampilan dan Perilaku Profesional) antara Stase Keperawatan Anak dengan Keperawatan Maternitas Sesudah Intervensi Metode Bimbingan One Minute Preceptor (OMP) pada Preceptor

Berdasarkan hasil penelitian yang peneliti lakukan diketahui bahwa terdapat perbedaan pencapaian kompetensi mahasiswa ners (komunikasi, keterampilan dan perilaku profesional) antara stase keperawatan anak dengan keperawatan maternitas sesudah intervensi metode bimbingan One Minute Preceptor (OMP) pada preceptor $(\mathrm{p}=<0,05)$.

Berdasarkan skor komunikasi, keterampilan dan perilaku profesional pada mahasiswa, peneliti menemukan bahwa nilai komunikasi, keterampilan dan perilaku profesional mahasiswa stase keperawatan maternitas selalu lebih tinggi dibandingkan dengan mahasiswa stase keperawatan anak.

Berdasarkan analisis kuesioner yang peneliti lakukan, penyebab adanya perbedaan hasil dari OMP yang telah diterapkan oleh prceptor yaitu dapat dikaitkan dengan karakteristik preceptor. Seperti tingkat pendidikan dan lama menjadi preceptor.

Tingkat pendidikan preceptor mahasiswa stase keperawatan maternitas sebagian besar adalah S2 dan dengan lama menjadi prceptor sudah 6-10 tahun. Menurut Mulyanti (2017), pendidikan yang dimiliki seseorang dapat mempengaruhi wawasannya sehingga lebih mudah dalam menerima serta menerapkan hal baru yang diketahuinya. Lama menjadi preceptor akan mempengaruhi pengalaman yang dimiliki oleh preceptor sehingga preceptor menjadi lebih memahami dan terampil dalam menrapkan metode bimbingan One Minute Preceptor (OMP).

Namun demikian, untuk memaksimalkan hasil dari penerapan OMP pada prceptor yang masih minim pengalaman, diharapkan dapat dilakukan kegiatan diskusi dan tukar fikirian bersama oleh seluruh preceptor yang ada di RSUD Arga makmur Bengkulu Utara.

\section{SIMPULAN}

1. Rerata nilai post test pengetahuan, sikap, keterampilan dan kumulatif preceptor lebih tinggi dibandingkan dengan nilai pre test. Rerata pencapain 
Emi Pebriani, Yulastri Arif dan Mira Susanti, Perbedaan Pencapaian Kompetensi Mahasiswa Ners (Komunikasi, Keterampilan dan Perilaku Profesional) Antara Stase Keperawatan Anak Dengan Keperawatan Maternitas Sesudah Intervensi Metode Bimbingan One Minute Preceptor (OMP) pada Preceptor di Kota Bengkulu

nilai komunikasi, keterampilan dan perilaku profesional mahasiswa stase keperawatan maternitas lebih tinggi daripada mahasiswa stase keperawatan anak.

2. Ada perbedaan pencapaian kompetensi mahasiswa ners (komunikasi, keterampilan dan perilaku profesional) antara stase keperawatan anak dengan keperawatan maternitas sesudah intervensi metode bimbingan One Minute Preceptor (OMP) pada preceptor.

\section{DAFTAR PUSTAKA}

Abreu, W. C. De, \& Interpeler, S. S. (2015). Effective Mentorship to Improve Clinical Decision Making and a Positive Identity: A Comparative Study in Turkey and Portugal, 5(1), 1-5. https://doi.org/10.7763/IJIET.2015.V5.473

Ahmar, H., Budi, P., Ahmad, M., Mushawwir, A., \& Khaidir, Z. (2020). Penerapan Model Pembelajaran Problem Based Learning : Literature Review. Jurnal Keperawatan Muhammadiyah, 10-17. Retrieved from http://journal.umsurabaya.ac.id/index.php/JKM

Arya, V., Gehlawat, V. K., Verma, A., \& Kaushik, J. S. (2018). Perception of One-Minute Preceptor (OMP) Model as a Teaching Framework among Pediatric Postgraduate Residents: A Feedback Survey. Indian Journal of Pediatrics, 85(7), 598. https://doi.org/10.1007/s12098-018-2622-3

Cholifah, N., Rusnoto, \& Hartinah, D. (2015). Bedside Sebagai Suatu Inovasi Metode Bimbingan Klinik Dalam kebidanan dan keperawatan, 6(2).

Fagundes, E. D. T., Ibiapina, C. C., Alvim, C. G., Fernandes, R. A. F., Carvalho-Filho, M. A., \& Brand, P. L. P. (2020). Case presentation methods: a randomized controlled trial of the one-minute preceptor versus SNAPPS in a controlled setting. Perspectives on Medical Education, 9(4), 245250. https://doi.org/10.1007/s40037-020-00588-y

Gatewood, E., \& De Gagne, J. C. (2019). The oneminute preceptor model: A systematic review. Journal of the American Association of Nurse Practitioners, 31(1), 46-57. https://doi.org/10.1097/JXX.0000000000000099

Goodman, M. S., \& Thompson, V. S. (2018). Public Health Research Methods for Partnerships and Practice. (M. S. Goodman \& V. S. Thompson, Eds.), Public Health Research Methods for Partnerships and Practice. New York: CRC Press. https://doi.org/10.1201/9781315155722

Ismail, L. M. (2016). Clinical instructor' s behavior : Nursing student, $s$ perception toward effective clinical instructor, $\mathrm{s}$ characteristics, 6(2). https://doi.org/10.5430/jnep.v6n2p96

Kholifah, S., \& Kusumawati, W. (2016). Hambatan Lulusan Ners Dalam Menghadapi Uji Kompetensi
Ners Indonesia. The Indonesian Journal of Health Sciencehe, 7(1), https://doi.org/10.32528/the.v7i1.383

Kurniadi, A. (2018). Etika dan hukum keperawatan. Depok: Rajagrafindo Persada.

Li-Ling, H. (2014). Clinical teaching competence inventory for nursing preceptors: Instrument development and testing, 46(2), 214-224.

Lockspeiser, T. M., \& Kaul, P. (2015). Applying the One Minute Preceptor Model to Pediatric and Adolescent Gynecology Education. Journal of Pediatric and Adolescent Gynecology, 28(2), 7477. https://doi.org/10.1016/j.jpag.2014.07.014

McSharry, E., \& Lathlean, J. (2017). Clinical teaching and learning within a preceptorship model in an acute care hospital in Ireland; a qualitative study. Nurse Education Today, 51, 73-80. https://doi.org/10.1016/j.nedt.2017.01.007

Notoatmodjo, S. (2016). Metodologi Penelitian Kesehatan. Jakarta: PT Rineka Cipta.

Odelius, A., Traynor, M., Mehigan, S., Wasike, M., \& Caldwell, C. (2017). Implementing and assessing the value of nursing preceptorship. Nursing Management, 23(9), 35-37. https://doi.org/10.7748/nm.2017.e1547

Rohmah, N., \& Walid, S. (2019). Proses Keperawatan Berbasis KKNI (Kerangka Kualifikasi Nasional Indonesia) (1st ed.). Malang: Edulitera.

Sears, N. A. (2015). Examining the relationships between NCLEX-RN performance and nursing student factors, including undergraduate nursing program performance: A systematic review, (October). https://doi.org/10.5430/jnep.v5n11p10

Seki, M., Otaki, J., Breugelmans, R., Komoda, T., Nagata-Kobayashi, S., Akaishi, Y., ... Izumi, M. (2016). How do case presentation teaching methods affect learning outcomes?-SNAPPS and the One-Minute preceptor. BMC Medical Education, $\quad 16(1), \quad 1-7$. https://doi.org/10.1186/s12909-016-0531-6

Sugiono. (2018). Metode Penelitian Kualitatif. Bandung: Alfabeta CV.

Sugiyono. (2017). Metode Penelitian Kuantitatif, kualitatif dan $R \& D$. Bandung: Alfabeta, cv.

Sulung, N. (2016). Efektifitas metode preseptor dan mentor dalam meningkatkan kompetensi perwat klinik. Jurnal IPTEKS Terapan, 9, 224-235. https://doi.org/http://dx.doi.org/10.22216/jit.2015. v9i3.416

Swarjana, I. K. (2015). Metodologi Penelitian Kesehatan (2nd ed.). Yogyakarta: Andi.

Swartz, M. K. (2016). Revisiting "The One-Minute Preceptor." Journal of Pediatric Health Care, 30(2), 95-96. https://doi.org/10.1016/j.pedhc.2016.01.002

Syarli, S., Arif, Y., Fatmadona, R., \& Arini, L. (2020). 
Emi Pebriani, Yulastri Arif dan Mira Susanti, Perbedaan Pencapaian Kompetensi Mahasiswa Ners (Komunikasi, Keterampilan dan Perilaku Profesional) Antara Stase Keperawatan Anak Dengan Keperawatan Maternitas Sesudah Intervensi Metode Bimbingan One Minute Preceptor (OMP) pada Preceptor di Kota Bengkulu

Studi Komparatif Efektifitas Model Pembelajaran Klinik One Minute Preceptor ( OMP) Dan SNAPPS Terhadap Pencapaian Kompetensi Mata Kuliah Kepemimpinan dan Ma- najemen Keperawatan Mahasiswa Profesi Ners FKep Unand, 5(1).

Teferra, A. A., \& Mengistu, D. (2019). Knowledge and Attitude Towards Nursing Clinical Preceptorship Among Ethiopian Nurse Educators: An Institution-Based Cross-Sectional Study International Journal of Africa Nursing Sciences Knowledge and attitude towards nursing clinical preceptorship among. International Journal of Africa Nursing Sciences, 7(October 2017), 82-88. https://doi.org/10.1016/j.ijans.2017.10.001

Tim Visi Adiwidya. (2015). Panduan Lulusan UKNI Uji Kompetensi Ners Indonesia (Fitria Pra). Jakarta Selatan: Visimedia Pustaka.

Tuasikal, H. (2020). Efektivitas Metode One Minute Preceptor Terhadap Penalaran Klinis Mahasiswa DIII Keperawatan. Jurnal Keperawatan, 12(2), 245-252.

Tuasikal, H., \& Mukaromah, R. S. (2019). Efektivitas Strategi Pembelajaran Klinik Metode SNAPPS (Summarize, Narrow, Analyze, Proba, Plan) Terhadap Penalaran Klinis Pada Mahasiswa Praktek Klinik: Systematic Review. Jurnal Ilmiah Ilmu Keperawatan Indonesia, 9(3), 628-634. https://doi.org/10.33221/jiiki.v9i03.345

Ward, A., \& McComb, S. (2017). Precepting: A literature review. Journal of Professional Nursing, 33(5),

314-325. https://doi.org/10.1016/j.profnurs.2017.07.007

Wisman, R. (2019). Dari Berfikir Positif ke Bertindak Positif. Alvabet. Ciputat

Yusuf. (2015). Konsep dan Metoda Bimbingan Klinik Keperawatan. 